\title{
A longitudinal study of exercise metabolism during recovery from viral illness
}

\author{
P. Jakeman PhD \\ School of Sport and Exercise Sciences, University of Birmingham, Birmingham, UK
}

\begin{abstract}
An élite athlete engaged in a longitudinal programme of physiological assessment suffered a loss of performance that was later ascribed to an asymptomatic viral illness. In this 15-month, single subject, repeated measures study it was possible to demonstrate a severe decrease of exercise performance following viral illness. The oxygen uptake equivalent to the onset of blood lactate accumulation of $4 \mathrm{mmoll}^{-1}$ (OBLA) decreased by $17 \%$ following viral illness, then recovered slowly, but had not returned to pre-viral levels 50 weeks later. Steady state exercise metabolism was also affected. During prolonged exercise at $70 \%$ of $\dot{V}_{\mathrm{O}_{2} \max }$ the proportion of energy derived from carbohydrate metabolism increased and an inability to maintain euglycaemia was observed. In both the graded and prolonged exercise tests, a pronounced tachycardia was evident after viral illness, possibly as a result of a febrile response to the infection, or, a direct effect of the virus upon myocardial performance. These data provide some preliminary and unique findings of the effects of viral illness upon the physiological and metabolic responses to exercise in an élite athlete. The data also demonstrate the sensitivity of currently used laboratory measures of exercise performance to monitor the changes in physiological function during recovery from viral illness.
\end{abstract}

Keywords: Viral illness, metabolism, cycling, performance

High-intensity or high-volume training has been reported to increase the incidence of viral and other infectious illnesses among many athletes engaged in training and competition ${ }^{1-3}$ which may lead to a serious and long-term reduction in athletic performance. The symptoms of a protracted illness in some athletes can resemble those of 'chronic fatigue' ${ }^{4}$ or 'post-viral fatigue syndrome's. Though no reduction in muscle strength or fatiguability has been found in patients with post-viral fatigue ${ }^{6}$ subtle changes in hypothalamic function ${ }^{7}$ and skeletal muscle metabolism $^{8,9}$ may persist for several months after the initial infection subsides.

Rarely is there an opportunity to study the physiological changes that result from viral infection

Address for correspondence: Dr P. Jakeman, Applied Physiology Research Unit, School of Sport and Exercise Sciences, University of Birmingham, Edgbaston, Birmingham B15 2TT, UK

(C) 1993 Butterworth-Heinemann Ltd 0306-3674/93/030157-05 in an élite athlete. Most often the athlete will attend for physiological assessment only after he or she develops an unexplained lack of form. In these cases there is often a lack of detailed physiological data pertaining to the athlete's 'in form' condition with which to compare the effects of the infectious illness. This approach rarely provides adequate evidence of a reduction in physiological function and/or exercise performance resulting directly from the onset of viral infection.

The focus of this report is the physiological and metabolic data obtained from an élite road cyclist who contracted a viral infection (unknown to both athlete and scientist) while engaged in a longitudinal programme of physiological investigation. Detailed data regarding the physiological response to maximal and submaximal exercise were therefore available before, during and after infection. All post-infection trials were performed after a thorough clinical examination had been performed.

\section{Methods}

The subject of this report is a 24-year-old male élite road cyclist engaged in training for national and international competition. The competitive event is the $100-\mathrm{km}$ road race requiring the ability to sustain a power output in excess of $300 \mathrm{~W}$ for up to $4 \mathrm{~h}$ depending upon the prevailing conditions. These data were obtained over a 15 -month period beginning in March. The training load at this phase of the training cycle was not considered to be high by the athlete or coach.

\section{Experimental protocol}

Maximal oxygen uptake ( $\dot{V}_{\mathrm{O}_{2} \text { max }}$ protocol A) and the onset of blood lactate accumulation (OBLA; protocol B) were last measured 4 weeks before the recognition of viral illness. Steady state submaximal tests (protocol C) were performed before and during the infectious illness with 7 days intervening between these two tests. The results of the second of these two tests prompted clinical examination and viral antibody studies. Though clinical examination was singularly unrewarding, raised antibodies to Coxsackie (titres $>300$ ) were subsequently confirmed. OBLA was then reassessed 1, 10, 20 and 50 weeks after the toxic phase of the illness had passed. In the 
absence of any elevation of body temperature or resting heart rate, the subject resumed light training after 1 week and had returned to full training after 4 weeks of recovery.

All exercise tests were performed by the subjects riding their own racing bike on a motorized treadmill (Woodway, XEGL2, Weil-am-Rhein, Germany) at 17 m.p.h. with a fixed incline of $3 \%$. The pedal cadence was maintained at 88 r.p.m. by selection of appropriate gearing. A linear increase in exercise intensity was obtained by the addition of weights to a pulley system attached to the rear of the bike (Figure 1). A 20 -min warm-up at 17 m.p.h. at $3 \%$ incline with a $1.0 \mathrm{~kg}$ weight attached to the pulley, requiring $60 \%$ of $\dot{V}_{\mathrm{O}_{2} \max }$ was performed before each exercise test. The subject also undertook a 7-day weighed food intake before the start of the study and maintained the same food intake for 3 days before each exercise test which was performed in the morning after an overnight fast.

\section{Protocol $A$-measurement of maximal oxygen uptake} $\left(\dot{V}_{\mathrm{O}_{2} \max }\right)$

This test consisted of successive 3-min stages in which the weight added to the pulley was increased by $0.5 \mathrm{~kg}$ per stage until exhaustion. Expired gas samples were collected during the last minute of each stage and for the last minute of exercise. Capillary blood samples $(2 \times 20 \mu \mathrm{l})$ were obtained within the last $30 \mathrm{~s}$ of each stage and at 3 and $5 \mathrm{~min}$ after exercise. Heart rate and rate of perceived exertion (RPE) were recorded at the end of each stage and at exhaustion.

\section{Protocol B-graded incremental exercise test}

This test consisted of six 10 -min stages ( 1 to 6 ) in which the weight added to the pulley was increased by $0.3 \mathrm{~kg}$ per stage calculated to increase the energy expenditure by $5 \%$ of $\dot{V} \mathrm{O}_{2}$ max per stage. Expired gas samples were collected over the last 2-3 min of each stage, capillary blood samples $(2 \times 20 \mu \mathrm{l})$ obtained during the last $30 \mathrm{~s}$ of each stage, and heart rate and $R P E$ recorded at the end of each stage.

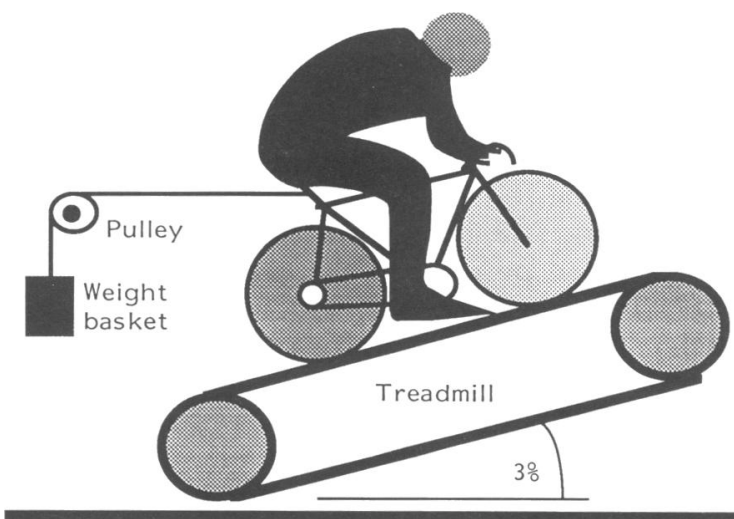

Figure 1. Treadmill cycle ergometry

\section{Protocol C - steady state submaximal exercise test}

This test consisted of $3 \mathrm{~h}$ at $17 \mathrm{~m} . \mathrm{p} . \mathrm{h}$. at $3 \%$ incline with a $1.0 \mathrm{~kg}$ weight attached to the pulley. The relative exercise intensity for this test was calculated to be $70 \%$ of maximal oxygen uptake $\left(\dot{V}_{\mathrm{O}_{2} \text { max }}\right)$. Expired gas samples were collected during the last $2-3 \mathrm{~min}$ of each $15-\mathrm{min}$ period of exercise, capillary blood samples $(2 \times 20 \mu \mathrm{l})$ were obtained during the last $30 \mathrm{~s}$ of each 15-min period and heart rate and RPE recorded at the end of each 15-min period.

\section{Indirect calorimetry}

The measurement of oxygen uptake and carbon dioxide excretion was performed using the Douglas Bag (Plysu, Milton Keynes, UK) technique according to the WHO recommendations ${ }^{10}$. The total energy expenditure was calculated by summation of the values obtained for each 15-min expired gas sample the percentage contribution of carbohydrate and fat to the metabolic mixture was calculated from the respiratory exchange ratio (RER).

\section{Analytical method}

Capillary blood samples were taken into heparinized capillary tubes, deproteinized in perchloric acid $(0.4 \mathrm{M})$, centrifuged at $5^{\circ} \mathrm{C}$ and the supernatant stored at $-20^{\circ} \mathrm{C}$ before enzymatic analysis of lactate and glucose $^{11}$.

\section{OBLA interpolation from lactic acid curves}

The blood lactate data from the graded exercise tests (protocol B) were plotted against oxygen uptake as the independent variable. The oxygen uptake equivalent to a reference blood lactate concentration of $4 \mathrm{mmoll}^{-1}$ was interpolated from the fitted curve (Figure 2).

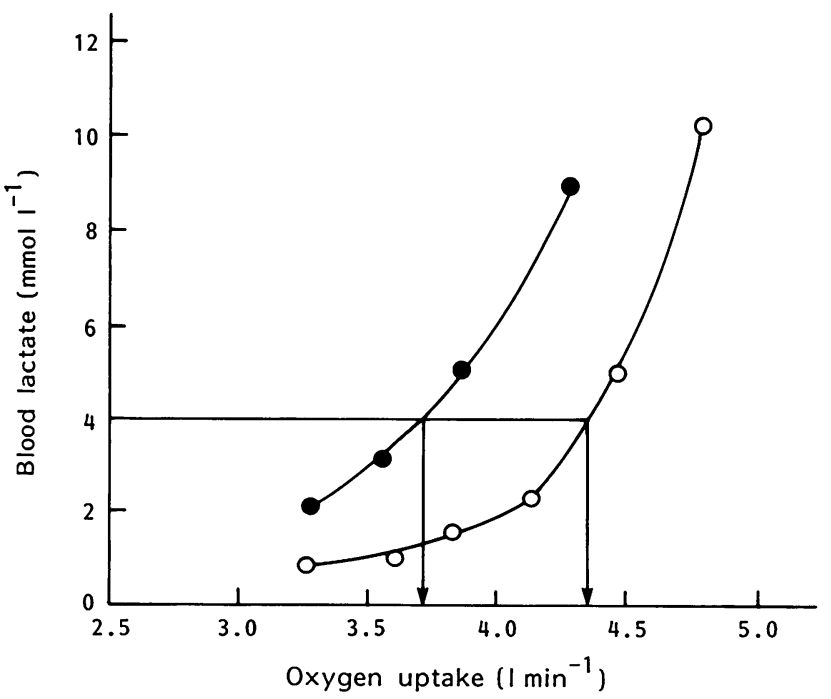

Figure 2. Interpolation of onset of blood lactate accumulation (OBLA) from blood lactate data before $\left(\mathrm{O}_{-} \mathrm{O}\right)$ and after (-) viral illness (for details see text) 
Viral illness and exercise metabolism: P. Jakeman

Table 1. Cardiovascular and metabolic responses to prolonged submaximal exercise at $70 \%$ of $\dot{V}_{\mathrm{O}_{2} \text { max }}$ before and after viral illness

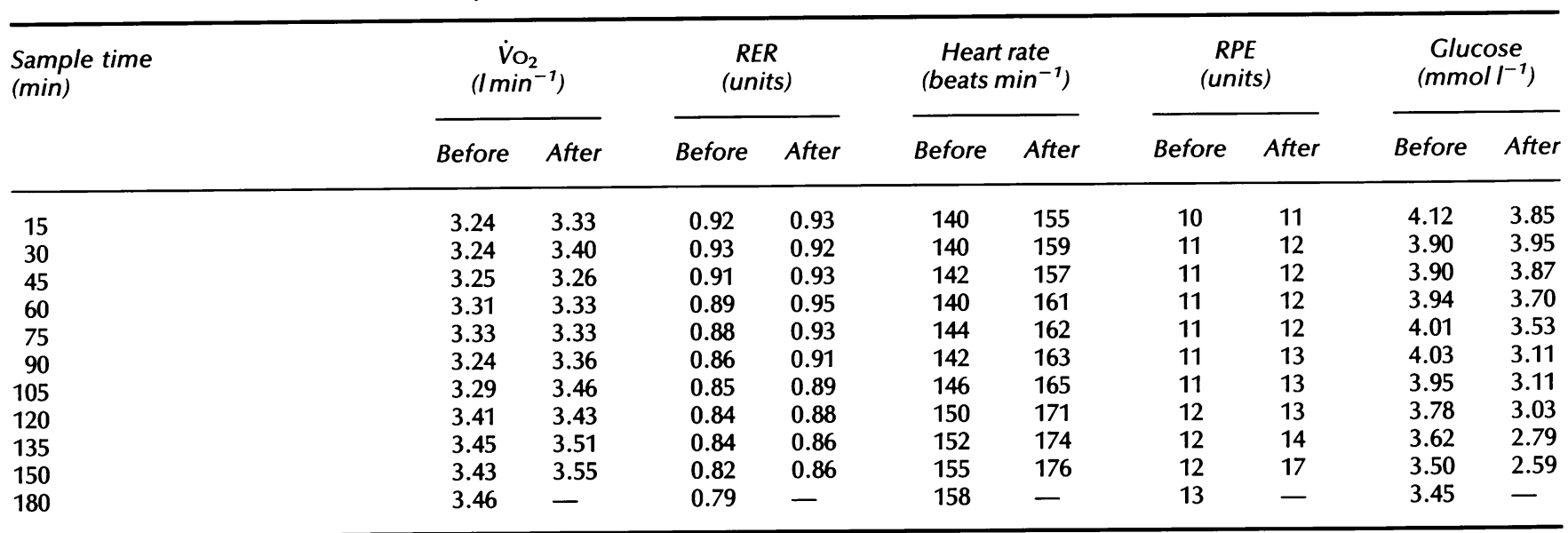

RER, respiratory exchange ratio; RPE, rate of perceived exertion

\section{Results}

Subject data. The following data were recorded 4 weeks before the viral illness. Height $176.4 \mathrm{~cm}$; weight $64.1 \mathrm{~kg}$; estimated body fat, $13.4 \%$; maximal oxygen uptake, $4.781 \mathrm{~min}^{-1}$; maximal heart rate 192 beats $\min ^{-1}$.

Prolonged submaximal exercise. A pronounced increase in heart rate and perceived exertion ratings in the post-viral trial led to the test being terminated by the experimenter after $150 \mathrm{~min}$ (Table 1). As indicated by the change in RER, prolonged submaximal exercise produced a shift in substrate utilization towards a higher percentage of fat oxidation with time. The contribution of fat as a metabolic fuel in the pre-exercise trial increased from $27 \%$ after $15 \mathrm{~min}$ of exercise to $70 \%$ after completion of $3 \mathrm{~h}$. Fat oxidation during the post-viral trial was increased from $23 \%$ after $15 \mathrm{~min}$ to $47 \%$ after $150 \mathrm{~min}$ of exercise. Over an equivalent time period (i.e. $150 \mathrm{~min}$ ) fat oxidation in the pre-viral trial accounted for $60 \%$ of the total oxidative metabolism. Resting blood glucose was slightly higher at rest (4.42 versus $\left.4.61 \mathrm{mmoll}^{-1}\right)$ in the post-viral trial but, whereas euglycaemia was effectively maintained in the pre-viral trial, the blood glucose concentration decreased markedly after $60 \mathrm{~min}$ of exercise after viral illness.

Graded exercise tests. Compared to the pre-viral test, the subject was unable to complete the graded exercise protocol after the infectious illness managing to complete only four of the six stages of the test 1 week post-infection and five of the six stages thereafter. There was a pronounced increase in heart rate at all levels of exercise after 1 week and 10 weeks of recovery which was less evident during stages 1 to 6 after 50 weeks' recovery (Table 2). Near maximal heart rates were attained during the final stage of the graded exercise test at all days of measurement. The blood lactate values were also significantly higher at all stages of the graded exercise test after infection, the interpolated values revealing a $17 \%$ change 1 week after the illness and gradually returning to normal after 50 weeks of recovery (Table 3).

Table 2. Heart rate and blood lactate during graded incremental exercise measured before and during recovery from viral illness

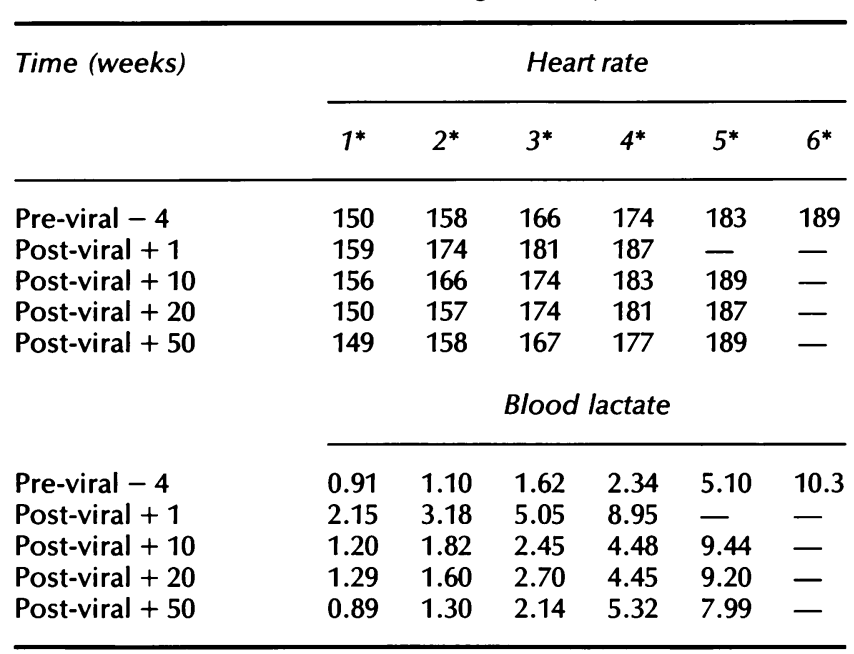

*Exercise stage

Table 3. Maximal oxygen uptake and onset of blood lactate accumulation (OBLA) before and during recovery from viral illness

\begin{tabular}{llc}
\hline & \multicolumn{2}{c}{ Performance data } \\
\cline { 2 - 3 } Time (weeks) & $\begin{array}{c}\dot{V}_{\mathrm{O}_{2 \max }} \\
\left(1 \min ^{-7}\right)\end{array}$ & $\begin{array}{c}\text { OBLA } \\
\left(\% \dot{V}_{\mathrm{O}_{2} \text { max }}\right)\end{array}$ \\
\hline Pre-viral -4 & 4.78 & 94 \\
Post-viral + & $4.28^{*}$ & 77 \\
Post-viral + 10 & $4.30^{*}$ & 81 \\
Post-viral + 20 & $4.57^{*}$ & 84 \\
Post-viral + 50 & $4.65^{*}$ & 88 \\
\hline${ }^{*} \dot{V}_{O_{2} \text { peak }}$ & &
\end{tabular}




\section{Discussion}

The post-viral cardiovascular response to exercise shows a marked tachycardia which could have been the result of an increased cardiac output to satisfy thermoregulatory requirements to an elevated body temperature. Though tenable, this explanation could not account for the non-linear heart rate response (HRR) to increasing exercise intensity observed after viral illness (Figure 3 ). This abnormal response could be indicative of a decrease in myocardial performance, possibly caused by the preference of the Coxsackie virus for the heart muscle and possibly leading to myocarditis or pericarditis. Clinical electrocardiographic studies during exercise did not however reveal any abnormality in this subject.

The post-viral pattern of metabolic response to exercise in this study indicates a pronounced effect upon carbohydrate metabolism characterized by a greater use of carbohydrate as a metabolic fuel - a failure to maintain euglycaemia and an increase in anaerobic glycolysis resulting in higher blood lactate. Infectious illness can initiate a broad and complex array of metabolic responses ${ }^{12}$ some of which are directly related to the specific host defense mechanisms while others contribute to the maintenance of body homeostasis, the provision of metabolizable energy and the synthesis of acute phase proteins. Hormones that regulate carbohydrate metabolism are intimately involved in the host defence response to infectious illness. Decreased carbohydrate tolerance and hyperinsulinaemia often result after viral illness ${ }^{13}$ - findings that are consistent with recent reports of severe and long lasting insulin resistance ${ }^{14}$, possibly as a result of elevated levels of hormones antagonistic to insulin such as cortisol, glucagon and growth hormone. The combined effect of these hormonal responses to viral illness would be to increase the availability of glucose at the expense of glucose storage. The observation that insulin resistance has no effect upon oxidative disposal of glucose but effects an apparent block on glucose storage would support this view ${ }^{15}$. The resultant hyperglycaemia and glucose intolerance during the early

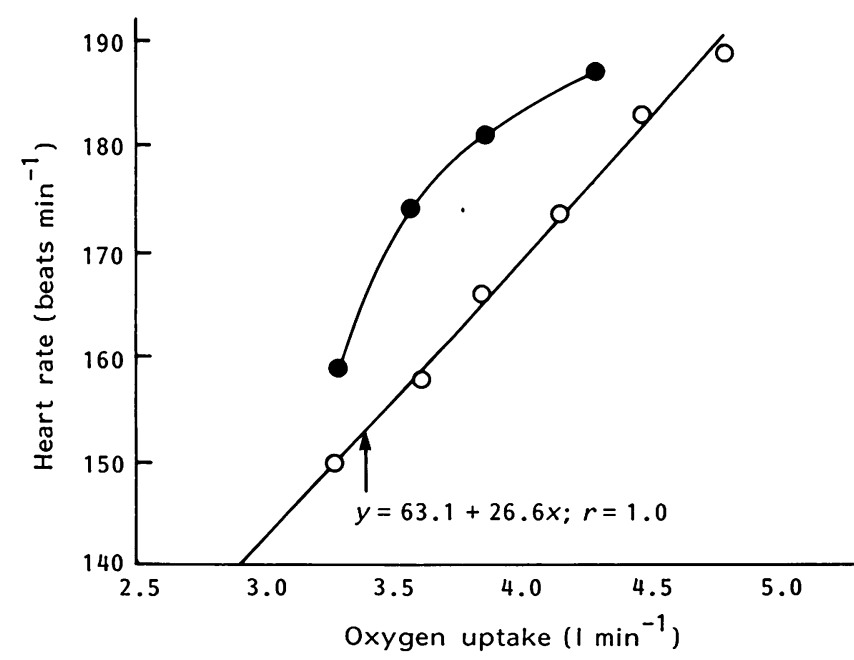

Figure 3. Heart rate relationship to oxygen uptake before $\left(\mathrm{O}^{-} \mathrm{O}\right)$ and after $\left(\mathrm{O}^{-}\right)$viral illness stages of an infectious illness can reverse to hypoglycaemia and depletion of tissue carbohydrate during persistent infectious illness. The combined effect of viral illness and exercise, which is known to have an insulin-like effect, would accelerate the uptake and oxidation of blood glucose. Failure to maintain euglycaemia during exercise, as was observed in this study, could therefore result from lower basal levels of liver glycogen and increased demand for glucose as an oxidizable fuel.

An alternative explanation for the increased carbohydrate oxidation during prolonged exercise could be a failure in the relative contribution of fat oxidation to overall energy metabolism. Lipolysis of triglycerides stored in adipose tissue is accelerated during exercise by an increase in the activity of adipose cell, or hormone sensitive lipase (HSL), resulting in up to a five-fold increase in the circulating level of free fatty acids. This rise in free fatty acids is mediated by the combined effects of an increasing $\beta$-adrenergic stimulus to the adipocyte and a decline in the circulating insulin during prolonged exercise ${ }^{15}$. Though little is known about the actual process by which free fatty acids are taken up by skeletal muscle, the increase in the presentation of free fatty acids to the muscle (i.e. flow $\times$ concentration) during exercise is known to produce a corresponding increase in their uptake and oxidation ${ }^{16}$. The shift in substrate for exercising muscle to a higher percentage of fat oxidation reduces the rate of muscle glycogen utilization and increases the duration for which exercise can be performed ${ }^{17}$. Though the circulating glycerol and fatty acid concentrations were not measured in this study and the exercise response of fatty acid mobilization after viral illness is unknown, the resting levels of serum fatty acids are known to be lowered in severe acute and chronic viral infections $\mathrm{s}^{18}$, and may remain low for some time after the acute phase of the infection has passed ${ }^{19}$.

The onset of blood lactate accumulation is frequently used as a determinant of endurance performance in well-trained cyclists ${ }^{20}$. Recent reports of a high correlation between muscle and blood lactate concentration during incremental exercise has been interpreted to indicate that the blood lactate threshold corresponds to the muscle lactate threshold ${ }^{21}$. The increased production of lactate for the same absolute exercise intensity after viral illness implies either an accelerated flux through glycolysis or decrease in the rate of entry of pyruvate for mitochondrial oxidation. The short time period of detraining after viral illness (10 days) is unlikely to account for the observed changes in OBLA and, although there is insufficient evidence from the present study to support the hypothesis that the increase in blood lactate is linked to abnormal metabolism of muscle per se, it is possible that the oxidative capacity of muscle could be affected after viral illness ${ }^{22}$ thereby requiring a greater contribution from anaerobic glycolysis to maintain the rate of adenosine triphosphate resynthesis and causing an increase in muscle acidosis ${ }^{8}$. Alternatively, diversion of glucose away from carbohydrate oxidation could lead to an increased blood lactate concentration. The mechanism of action for such an effect could be 
similar to that induced by septicaemia ${ }^{23}$ and mediated via a change in activity of the pyruvate dehydrogenase complex thereby limiting the rate of pyruvate oxidation.

In summary, the data from this study show a pronounced change in physiological correlates of endurance performance following viral infection. The data also provide a warning to both athletes and their coaches of the potential damage that could occur if athletes attempt to 'run off a cold' or other infectious illness. Though limited in number these data warrant a more detailed investigation of the mechanism by which viral illness affects sporting performance and the time course of recovery from viral illness.

\section{Acknowledgements}

The author wishes to thank Dr D. Ashton and Dr B. Davies for their help in this study.

\section{References}

1 Roberts JA. Viral illness and sports performance. Sports Med 1986; 3: 296-303.

2 Fitzgerald L. Exercise and the immune system. Immunol Today 1988; 9: 337-9.

3 Fitzgerald L. Overtraining increases the susceptibility to infection. Int J Sports Med 1991; 12 (Suppl 1): S5-S8.

4 Holmes GP, Kaplan JE, Gantz NM et al. Chronic fatigue syndrome a working case definition. Ann Intern Med 1988; 108: 387-9.

5 Sharpe MC, Archard LC, Banatvala JE et al. A report - chronic fatigue syndrome: guidelines for research. J Royal Soc Med 1991; 84: 118-21.

6 Rutherford OM, White PD. Human quadriceps strength and fatiguability in patients with post viral fatigue. I Neurol Neurosurg Psychiatry 1991; 54: 961-4.

7 Bakheit AMO, Behan PO, Dinan TG, Gray CE, O'Keane VO. Possible upregulation of hypothalamic 5-hydroxytryptamine receptors in patients with post-viral fatigue syndrome. $B M]$ 1992; 304: 1010-12.
8 Arnold DL, Bone PJ, Radda GK, Taylor DJ. Excessive intracellular acidosis of skeletal muscle on exercise in a patient with post-viral fatigue syndrome. Lancet 1984; i: 1367-9.

9 Byrne E, Trounce I. Chronic fatigue and myalgia syndrome: mitochondrial and glycolytic studies in skeletal muscle. $J$ Neurol Neurosurg Psychiatry 1987; 50: 743-6.

10 Andersen KL, Shephard RJ, Denolin H, Varnaukas E, Masironi R. Fundamentals of Exercise Testing. Geneva, Switzerland: WHO, 1971: 58-73.

11 Maughan RJ. A simple, rapid method for the determination of glucose, lactate, pyruvate, alanine, 3-hydroxybutyrate and acetoacetate on a single $20-\mu$ l blood sample. Clin Chim Acta 1982; 122: 231-40.

12 Beisel WR. Metabolic responses to infection. Ann Rev Nutr 1975; 26: 9-20.

13 Rayfield EJ, Cunrow RT, George DT, Beisel WR. Impaired carbohydrate metabolism during a mild viral illness. $N$ Engl J Med 1973; 289: 618-21.

14 Jki-Jarvinen $\mathrm{H}$, Sammalakorpi $K$, Koivisto VA, Nikkila EA. Severity, duration and mechanism of insulin resistance during acute infections. J Clin Endocrinol Metab 1989; 69: 317-23.

15 Galbo H. Hormonal and Metabolic Adaptations to Exercise. New York, USA: Thieme-Stratton, 1983: 64-7.

16 Hagenfeldt $\mathrm{L}$. Turnover of individual free fatty acids in man. Federation Proc 1975; 34: 2236-40.

17 Hickson RC, Rennie MJ, Conlee RK, Winder WW, Holloszy JO. Effects of increased plasma fatty acids on glycogen utilization and endurance. J Appl Physiol 1977; 43: 829-33.

18 Stroesser AV. Effect of acute infection on iodine number of serum fatty acids. Proc Soc Exp Biol Med 1935; 32: 1326-7.

19 Williams LL, Doody DM, Horrocks LA. Serum fatty acid proportions are altered during the year following acute Epstein-Barr virus infection. Lipids 1988; 23: 981-8.

20 Coyle ED, Coggan AR, Hopper MK, Walters TJ. Determinants of endurance in well-trained cyclists. J Appl Physiol 1988; 64: 2622-30.

21 Chwalbinska-Moneta J, Robergs RA, Costill DL, Fink WJ. Threshold for muscle lactate accumulation during progressive exercise. J Appl Physiol 1989; 66: 2710-16.

22 Astrom E, Friman G, Pilstrom L. Effect of viral and mycoplasma infections on ultrastructure and enzyme activities in human skeletal muscle. Acta Pathol Microbiol Scand 1976; 84: 113-22.

23 Vary TC. Increased pyruvate dehydrogenase kinase activity in response to sepsis. Am J Physiol 1991; 260 (Endocrinol Metab 23), E669-74.

Among this year's categories for the Winston Churchill Memorial Travelling Fellowships is "Sports Injuries".

Applications close 29th October, 1993, details from:

The Winston Churchill Memorial Trust

15 Queen's Gate Terrace

London

SW7 5PR

Tel: 0715849315 